\title{
Low-grade energy of the ground for civil engineering
}

\author{
Natalia Potienko ${ }^{1,}{ }^{*}$, Nadezhda Kalinkina ${ }^{1}$, and Aleksandra Bannikova ${ }^{1}$ \\ ${ }^{1}$ Samara State Technical University, Institute of Architecture and Civil Engineering, \\ 194,Molodogvardeyskaya St, 443001, Samara, Russia
}

\begin{abstract}
The article researches issues related to the relevance of applying renewable energy sources for civil engineering. The aim of the work is the study of modern approaches to designing buildings, using low-grade energy of the ground. The research methodology is based on the complex analysis of international design experience and on identifying the strengths and weaknesses of objects that use low-grade heat. We have identified the prospects of applying it for domestic construction practice. The state policy in the field of the efficient use of energy resources has been analyzed, and the vector of energy-saving programs development for the Samara Region has been defined. The research describes the impact of using geothermal energy on the architectural and planning solutions of buildings, as well as the peculiar features of the latter's design, which are related primarily to the increase of energy efficiency. As a result, in the article a conclusion is made that the objects under investigation may be considered as one of the vectors of sustainable architecture development.
\end{abstract}

\section{Introduction}

At present, all over the world in energy industry a number of problems may be pointed out first, the problems connected with the limited amount of raw materials, and second - the ones connected with environment pollution. A special place in settling these issues belongs to alternative energy $[1,2]$. Renewable (regenerative) energy, in other words - "green energy" is a form of energy, produced from sources that are inexhaustible by human standards. Among renewable energy sources (RES) we may name the energy of the sun, water, wind, biomass, the thermal energy of the upper layers of the earth's crust and oceans [3]. Their main advantages are that they are inexhaustible, environment friendly, besides operating costs are low.

Along with the advantages, there are some drawbacks: the low specific density of energy per receiving unit area of the device, the irregularity of its supply in time, and high initial capital outlay [4,5]. Currently, 140 countries have already created and are actively developing projects of renewable technologies. The goal of most countries is to increase the use of RES up to $15-20 \%$ of the country's energy balance by 2020 , and in the EU countries -

*Corresponding author: natalia.potienko@mail.ru 
up to $40 \%$ by 2040 [6]. The volumes of used regenerative energy are determined by economic expediency and competitiveness with traditional energy technologies.

At the moment there is a huge gap between Russia and developed countries in the field of energy efficiency [7]. Since 2003, draft bills have been worked out, that provide for the development of RES in the Russian Federation [3]. In 2009 the Federal Law "On energy saving and increase of energy efficiency ..." was adopted, that created favorable economic, organizational and legal conditions for the increase of energy efficiency and for energy saving when resources are consumed. Energy efficiency and saving is the direction that has been forming the strategy of Russia's development since 2010.

At the moment the document "The main directions of state policy in the sphere of the increase of electrical energy efficiency, based on using renewable energy sources, for the period up to 2020" has been adopted, which describes the advantages for RES suppliers [8]. This draft bill's aim is to increase the share of unconventional and renewable sources in the energy balance of the Russian Federation up to $10 \%$ by 2020 [3]. The Russian Government has designed documents, valid until 2030 - rules governing the implementation of energy efficient technologies in Russia.

The research by McKinsey, dedicated to identifying the most attractive sectors of economy for the increase of energy efficiency, has allowed singling out three of the most promising areas: civil engineering (real estate); fuel energy production and industrial vehicle sector. In Russia, energy consumption for the construction and maintenance of buildings is much higher than in other countries, it's about $400 \mathrm{mln}$. tons of fuel oil equivalent a year, $90 \%$ of which goes to provide hot water and heating. According to World Energy Conference results, in countries with temperate climate one third of consumed energy is spent on heating buildings. In Europe the consumption of energy for buildings is about $40 \%$, in the US - $36 \%$ [8].

The inclusion of RES into the structure of the building affects not only engineering, but also space-planning solutions. Architects' aim, in this case, is to solve the matters of joining together the sources of renewable energy and architectural means, and that requires the knowledge of advanced technologies. This issue has been researched a lot. I.D. Bakiyeva, V.B. Svalova, A.V. Ryabov, O.K. Afanasieva deal with the matters of the use of renewable energy sources for increasing the energy efficiency of buildings [9, 10].

Works by G.V. Esaulov, L.B. Kologrivova, A.N. Remizov, E.Ju.Vityuk are dedicated to the study of the environmental aspects of energy-efficient buildings formation [11-14]. The main contribution to the scientific support for the development of engineering and technical application of geothermal energy sources for civil engineering was made by foreign scientists, among whom it's necessary to name J.W. Lund, L. Rybach and H. Ehhorn [1519]. G.P. Vasiliev, N.V. Shilkin, Yu.A. Tabunschikov, L.A. Ogurechnikov research the heating and cooling of buildings that consume low-grade thermal energy, and develop the mathematical models for the thermal regime of heat pump systems [20-22].

\section{Materials and Methods}

Currently, the most common RES are the sun and the wind, but the use of geothermal energy (GE) is also of considerable economic interest. GE is the heat coming from the layers of the earth, the temperature of which is higher than the temperature of the air on the surface. The carriers of geothermal energy are fluids and hard rock. The reserves of GE can be found almost all over Russia (within the temperature range from 30 to $200^{\circ} \mathrm{C}$ ). From 2000 to 2006 the annual global consumption volumes of low-grade thermal energy in the heat pump systems for the heating and cooling of buildings has grown by about $10 \%$. The use of low-grade heat in combination with heat pumps (HP) is of interest. Such 
technologies have been actively introduced for the support of the life cycle of residential and public buildings in Central and Northern Europe, the US, Japan [23].

Geothermal energy is divided into high (hydrothermal and petrothermal) and low-grade energy, connected with the maintenance of wells up to $400 \mathrm{~m}$ deep. All sources of lowgrade heat can be subdivided into two types: natural and artificial. If we speak about natural low-grade heat sources, geothermal sources and heat coming from the ground are of interest. Artificial sources are different thermal emissions from enterprises, emissions from ventilating and wastewater systems [1]. The peculiar feature of high energy is the possibility of its "direct" consumption.

In systems using low-grade energy of the ground for heating and water supply systems, higher coolant temperature is required. The idea of the heat pump, which converts lowgrade energy of the ground into high energy, was formulated in the middle of the 19th century already. At the moment in the US the annual growth of the number of geothermal heat pump systems (GHPS) is by about 50 thousand. About $50 \%$ of them are heat exchangers with vertical closed-loop systems, they use devices with horizontal closed-loop heat exchangers less often, and about $15 \%$ are open-loop systems [22]. The leading role in the design of such systems is played by climatic, hydro and geological conditions, the properties of the ground and its thermal capacity. All these characteristics directly affect the efficiency of plants.

\section{Results}

The use of low-grade thermal energy of the ground affects only the planning concept of the building and does not impose any restrictions on the formation of its architectural look. The main part of engineering equipment - various types of heat pumps and heat exchangers - are located below ground, also there are special technical devices in the housekeeping area of the building. The choice of geothermal system depends on the conditions of the construction site (climatic, geological, hydrogeological), on the type of building (its use, the floor area of the object), on the system's estimated capacity, on the priority need for cooling (air conditioning), or for base heat demand provision. The unit capacity of geothermal systems varies widely, depending on the type of building (from $5.5 \mathrm{~kW}$ for private housing to $150 \mathrm{~kW}$ for office and public buildings). For high-rise buildings, both public and private, it's characteristic to use closed-loop vertical ground heat exchangers. This is due to the need to use geothermal systems with high estimated capacity, depending on the object's large size (the floor area of the rooms that require heating or cooling), with the small developed area suitable for deeper location of heat exchangers under limited urban conditions. During the construction of buildings of this type a pile field is often used as the foundation structure, which may be used as a geothermal energy collector, and this allows reducing investment costs.

One of the best examples of a modern energy-active high-rise building is Manitoba Hydro Company Headquarters, that was built in 2009 in the city of Winnepeg, Canada (Fig. 1). The project has been praised by the international community - it was voted "Best highrise building in North and South America", it was awarded a prize by Environmental Protection Committee, and it passed the certification by «Leadership in Energy and Environmental Design» (LEED). It is an office building with the total floor area of 76500 $\mathrm{m}^{2}$ (22 floors, building height $-115 \mathrm{~m}$ ), characterized by a combination of passive heating and cooling systems with efficient heat supply system based on the use of geothermal energy (280 vertical closed-loop ground heat exchangers), condensation boilers and a recuperator of heat from discharged air, which has allowed reducing annual energy consumption up to $28 \mathrm{kWh} / \mathrm{m}^{2}$. These figures are significantly lower than the standard 
annual heat demand of $250 \mathrm{kWh} / \mathrm{m}^{2}$, typical for Winnipeg with its sharply continental climate, where the temperature differences during the year reach $70^{\circ} \mathrm{C}$ [24].
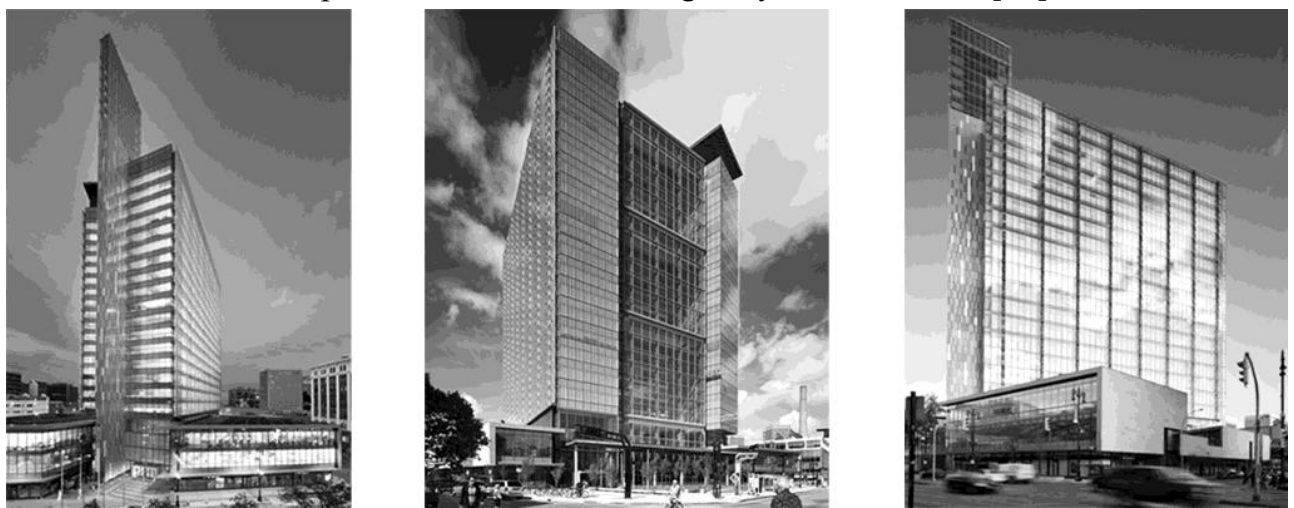

Fig. 1. Office Building Manitoba Hydro Place, Winninpeg, Canada, architects: Kuwabara Payne McKenna Blumberg Architects, Smith Carter Architects.

The use of horizontal ground heat exchangers is typical for objects with a large reserve of free space for the placement of horizontally laid heat exchangers in the surface layer of the ground. The power and efficiency of the energy plant depend on the length of pipes with circulating coolant, on water content in soil and on climatic conditions. Collectors of horizontal type are characterized by economic attractiveness - they require less investment compared to other types of geothermal plants, combined with relatively high seasonal efficiency and simple assembly. They are suitable for the organization of heat supply systems in low-rise houses and industrial buildings. The energy-efficient residential house «Ash + Ash» by Hennebery Eddy Architectural Bureau, built in Portland in 2014, received LEED platinum energy efficiency certificate, largely due to the use of a horizontal heat exchanger for running hot water system and horizontally arranged heating system (Fig. 2).
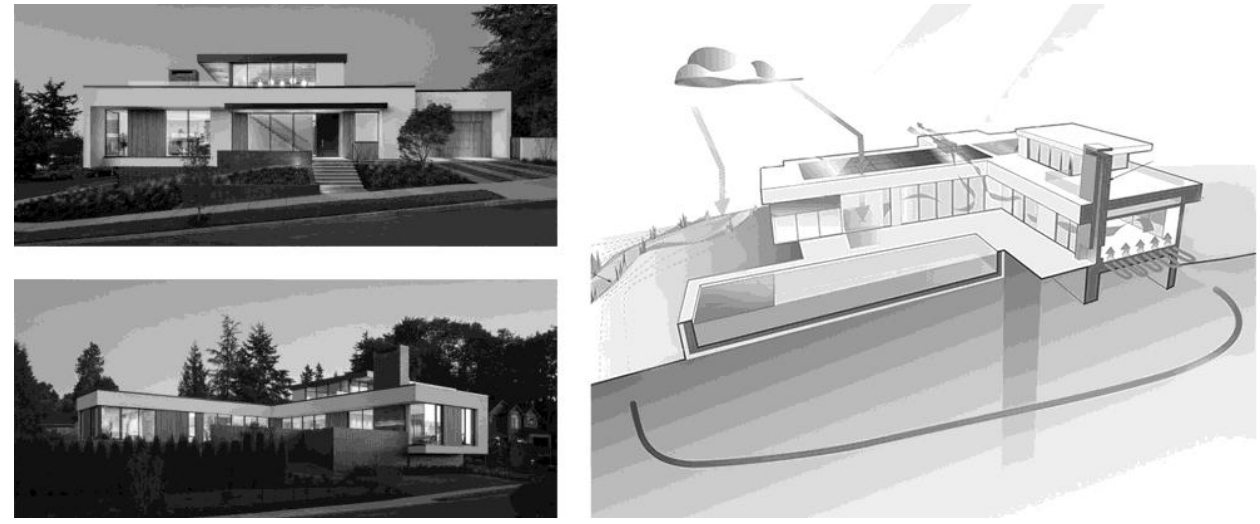

Fig. 2. Residential house «Ash + Ash» by Hennebery Eddy Architectural Bureau, Portland, the US

Another promising option of using horizontal collectors is foundation slabs activation the arrangement of a circulation circuit between soil and foundation [9]. The power of such a plant is lower than when the area next to the building is used, but there are significant advantages - no extra space for assembly is required, and costs for excavation are reduced. A typical example of using horizontal ground heat exchangers under the foundation is Siemens Headquarters in Munich, Germany. The use of geothermal energy is an important part of this building's climate control system. 
About 100000 liters of water per hour pass through the 70 kilometers of pipes laid under the foundation slab, and this water continuously circulates throughout the building and provides heating or cooling for its $45000 \mathrm{~m}^{2}$, depending on the season. So, the system consists of closed-loop horizontal ground heat exchangers, which in combination with building integrated photovoltaic roofing panels and secondary rainwater treatment, allows leading Siemens Headquarters to ultra-low energy consumption.

In individual housing, depending on the floor area of construction site, both vertically and horizontally laid heat exchangers may be used. «E + Green» is the first energy-efficient individual residential house, it was built in South Korea and it passed the certification of the German Passivhaus (Fig. 3).
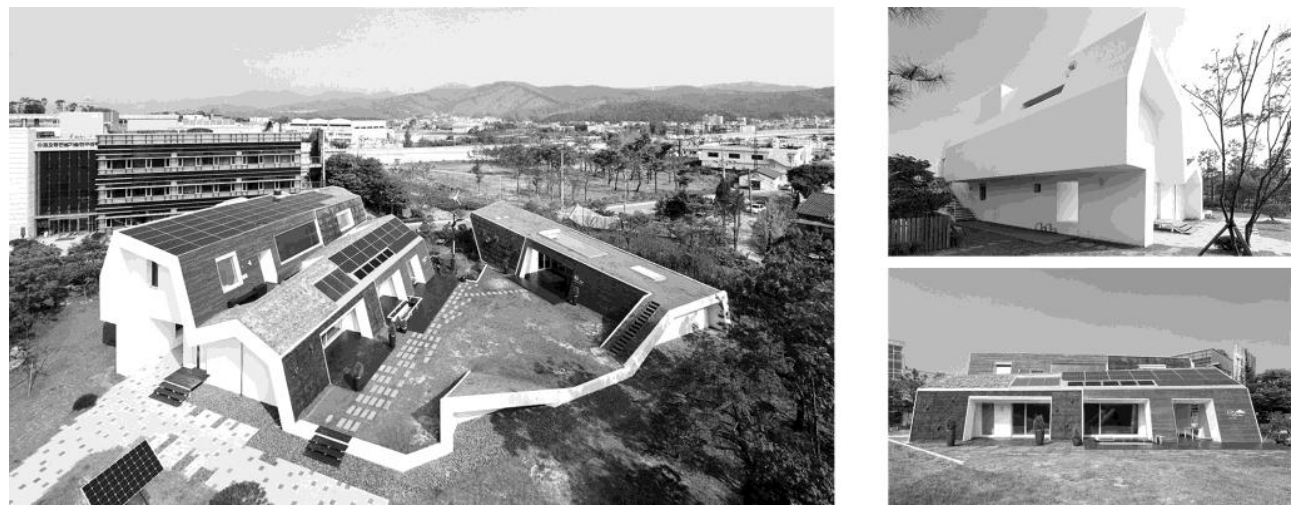

Fig. 3. The building «E + Green», Keyong, South Korea, by Unsangdong Architectural Bureau.

In this building, the floor area of which is $1733 \mathrm{~m}^{2}$, they use all the main types of alternative energy: solar, wind, geothermal. Another peculiar feature of this house is better heat and sound insulation, that is connected with the integration of the building into the landscape. The vertical closed-loop heat exchanger and the heat pump provide the heating and cooling of the house.

It is also possible to passively use the energy of the ground body as a geothermal collector, which will undoubtedly affect the space planning solution of the building. This technique is often used for low-rise buildings, due to the integration of some rooms into the natural landscape, or due to cushioning the building on unfavorable cardinal direction(s), in these cases the ground is a part of the enclosing structure, and it is a linking element with the natural environment. "Earthed" structires have their advantages, first of all they are connected to the high heat retention of the building, which allows reducing energy consumption for the operation. Space planning solution of the houses that use passive geothermal energy plays a critical role in their climatisation [3, 25]. Considering the experience of designing such buildings, two types of their formation may be pointed out with or without a courtyard (s). An interesting example of an "earthed" building with six courtyards is Harry Neville's residential house (Fig. 4). Due to the roof lanterns and glazing, that opens on the courtyards in the form of petals, favorable conditions of the indoor environment are created. 

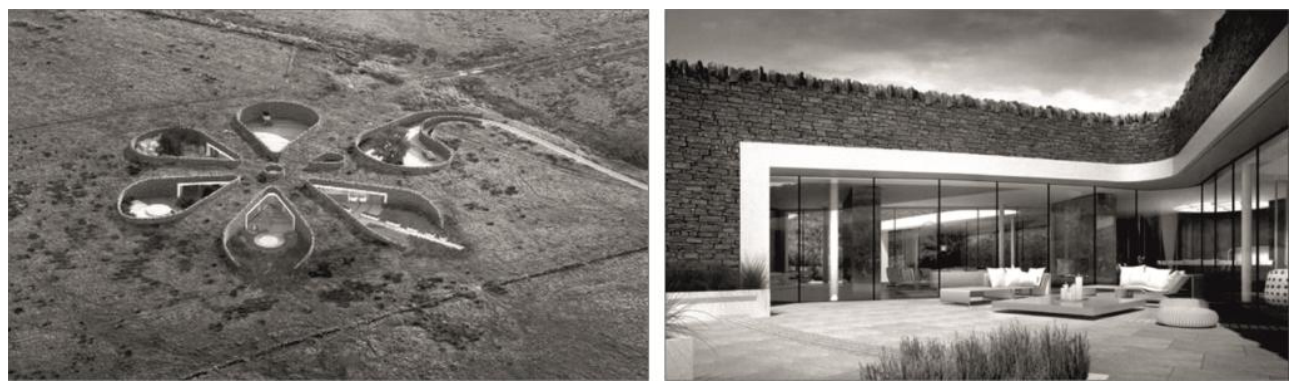

Fig. 4. Harry Neville's residential house, Bolton, Great Britain, by Make Architect Architectural Bureau

Researchers point out that our country has got huge potential for the development of energy-saving technologies. They predict that RES may give up to $40 \%$ of the energy produced. Vital energy-saving strategies are implemented in different regions of Russia. As part of the implementation of state programs, pilot regions have been selected for testing measures aimed at reducing energy consumption. In the Samara Region the municipal program "Energy saving and improvement of energy efficiency" has been adopted for 2014-2020, within the frames of which some objects that produce energy by means of RES already exist and some are planned for construction (Sanitary and epidemiological station in the city of Novokuibyshevsk, Sanitary and epidemiological station №2 in Samara).

A local example of using low-grade energy of the ground for high-rise residential buildings is a 17-storey energy-efficient house, that was constructed in the micro-district Nikulino-2 (Moscow) in 1998-2002 as a pilot project. The hot water supply system of the building consists of the main one (autonomous heat pump using vertical ground heat exchangers and emissions from ventilating systems) and backup (centralized) one. During the operation of the house, it was found that energy use in the heat pump system is cost-effective, and savings are up to $52.6 \%$. On this basis, we may talk about the expediency of using vertical ground heat exchangers for high-rise housing construction in Russia.

\section{Discussion}

In modern architecture the matter of integrating renewable energy sources into the structure of buildings is becoming more and more vital. The inclusion of RES into the structure of buildings affects the arrangement of the area and the building's orientation in space, as well as the object's planning concept, form-making and arrangement of rooms. The structural and engineering system is directly linked with the facade solution. Thus, the energy plant and the building should be treated as a single architectural object. Geothermal energy sources, which affect form-making to a lesser extent, more and more often become an integral part of structural and engineering solutions.

As mentioned earlier, the choice and efficiency of geothermal systems depends on climatic conditions to a very large extent. Also type of building, form of ownership and operating conditions play an important role. It is necessary to stress once again that the use of low-grade heat is efficient, safe and reliable for any types of objects. In order to minimize the disadvantages typical for the plants that use low-grade energy of the ground, it is advisable to combine them with other RES that are relevant for the region. Thus, the inclusion of renewable energy sources into the structure of architectural objects gives an impetus to the development of new approaches to designing "green" buildings. 


\section{Conclusions}

The analysis of domestic and international experience of designing objects with alternative energy sources has proved the relevance of new solutions and approaches to design in architecture. The use of RES is not only environment-friendly, it also allows using energy resources efficiently. Modern buildings are complexly arranged structures that have to meet a wide range of requirements (social, functional, constructive and technical, artistic and aesthetic). Constructive and technical requirements include the technical expediency of using this or that kind of equipment, the design features and the use of specific building methods. At present all large-scale energy saving programs implemented in other countries imply taking advantage of heat pump technology in heating and cooling systems.

At the moment the use of such systems in Central Russia is connected with high initial cash outlay that repays fast enough during the operation of objects. This proves the relevance of research in the field of efficient use of energy resources in architecture and civil engineering. Once again it should be pointed out that at the moment the most promising directions of improving the energy efficiency of buildings are: the reduction of energy consumption and energy losses; and the inclusion of RES into the structure of architectural objects. These trends make it possible, taking into account the current architectural and civil engineering requirements and environmental aspects of design, to open up the new creative potential of architectural activity.

\section{References}

1. A.V. Ryabov, Architectural form-making of buildings using alternative energy sources: dissertation in support of candidature for a technical degree (Moscow, 2012)

2. V. Ivanov, I. Bakhtina, T. Ivanova, S. Ilinykh, Urban Construction and Architecture 2, 88-93 (2015)

3. O.K. Afanasieva, Architecture of low-rise residential buidligns with renewable energy sources: dissertation in support of candidature for a degree in architecture (Moscow, 2009)

4. O.S. Popel, Energosvet 5, 22-26 (2011)

5. T.Ya. Vavilova, N.D. Potienko, I.V. Zhdanova, Procedia engineering 153, 938-943 (2016)

6. G. Sarkisian, Ya. Gorbatenko, Energy efficiency in Russia: hidden reserve (Moscow, Center for energy efficiency, 2009)

7. V. Generalov, E. Generalova, Urban Construction and Architecture 4, 23-29 (2015)

8. P.P. Bezrukih, S.M. Karabanov, Energy Bulletin, 21, 19-28 (2016)

9. I.D. Bakieva, Proceedings of Perm National Research Polytechnic University, Civil engineering and architecture 1, 123-130 (2016)

10. V.B. Svalova, International Scientific Journal for Alternative Energy and Ecology 7, 6979 (2009)

11. G.V. Esaulov, Proceedings of TSUAB, Architecture and urban planning 6, 9-24 (2014)

12. L.B. Kologrivova, Akademicheskij Vestnik URALNIIPROEKT RAASN 2, 73-75 (2013)

13. A.N. Remizov, Sustainable Architecture: Present and Future, Proceedings International Symposium 17-18 November 2011, Moscow Architectural Institute (State Academy) and Knauf Group CIS, 40-50 (2012)

14. E.Yu. Vityuk, Architecton 13, 45-50 (2010)

15. J. W. Lund, Design of closed-loop geothermal heat exchangers in the U.S. Course on geothermal heat pumps (2002).

16. J. W. Lund, T. L. Boyd, Proceedings World Geothermal Congress 2015 (2015) 
17. H. Ehhorn, J. Reiss, H. Kluttig, R. Hellwig, AVOK 2, 36 (2006)

18. L. Rybach, Proceedings European Geothermal Congress 2007 (2007)

19. B. Sanner, Ground Heat Sources for Heat Pumps (classification, characteristics, advantages) (2002)

20. L.A. Ogurechnikov, International Scientific Journal for Alternative Energy and Ecology 11, 58-66 (2005)

21. N.V. Shilkin, Methods to improve the thermal efficiency of buildings and their economic evaluation: dissertation in support of candidature for a technical degree (Moscow, 2007)

22. G.P. Vasiliev, Heating and cooling of buildings using low-grade thermal energy of the surface layers of the Earth: dissertation in support of candidature for a technical degree (Moscow, 2006)

23. S.P. Filippov, Energosvet 5, 42-46 (2011)

24. B. Kuwabara, T. Auer, T. Akerstream, G. Klym, M. Pauls, K. Opie, J. Peterson, Harnessing climate (High Performing Buildings, 2011)

25. A.O. Bannikova, N.A. Kalinkina. Urban Construction and Architecture 4, 34-38 (2016) 